\title{
Rancang Bangun Game Edumatika Berbasis Android
}

\author{
Bakuh Obed Samekto \\ Politeknik Negeri Malang \\ Email: bakuh.obed@gmail.com
}

\begin{abstract}
ABSTRAK. Pendidikan merupakan kebutuhan pokok yang harus dimiliki semua orang. Terutama berawal dari anak usia dini sekarang cenderung menyukai game yang akhirnya membuatnya lupa dalam pembelajaran dan membuat anak menjadi lebih malas untuk belajar. Sudah banyak anak - anak sekolah dasar sekarang yang menggunakan gadget untuk bermain game. Banyak orang tua pula menginginkan anaknya agar tidak melupakan belajarnya meski dalam bermain. Berdasarkan permasalahan diatas penulis memiliki ide untuk membuat penelitian yang berisikan tentang pembelajaran mengenasi anak usia dini untuk SD kelas 1. Pada penelitian ini penulis menggunakan penelitian berupa pembuatan Game Edumatika yang dibuat dan diimplementasikan berbais Game 2D, yang menggunakan metode Fuzzy Tsukamoto dan metode Linear Congruential Generator (LCG). Penerapan metode Fuzzy Tsukamoto ke dalam game untuk menentukan kondisi dari NPC (Non Player Character) dan metode Linear Congruential Generator (LCG) untuk pengacakan kemunculan item. Hasil dari penelitian ini berupa Game Edumatika yang memiliki tampilan keseluruhan yang menarik dan berjalan dengan baik. Pada game ini dirancang bukan hanya sebagai bahan hiburan saja melainkan juga terdapat pembelajaran. Dimana orang tua tidak perlu mengawatirkan anaknya untuk lupa dengan belajar, karena didalam game ini juga terdapat media pembelajaran dengan di akhir sebuah permainan terdapat pembelajaran untuk anak usia dini. Sehingga anak tidak merasa jenuh dalam belajar melainkan juga ada hiburan dari game tersebut.
\end{abstract}

Kata kunci: Game Edukasi, Platformer 2D Metode Tsukamoto, Metode LCG (Linear Congruential Generator)

ABSTRACT. Education is basic needs should be owned everyone. Especially started from early childhood now tending to love the game finally make it have forgotten learning and make the son to be more lazy to learn. There have been many children the primary school now using gadgets to play games. Many parents also want their children learning not to be forgotten even though in playing. Based on problems above writer had the idea to making researches that contains about learning about early childhood to grade 1 . In this study the use writers research study of of building games with doraemon made and implemented berbais $2 \mathrm{~d}$ game, which uses Fuzzy Tsukamoto method and Linear Congruential Generator (LCG) method. The application of Fuzzy Tsukamoto method into the game to determine the conditions of NPC (Non Player Character) and Linear Congruential Generator (LCG) method for randomizing the appearance of items. The result of this study of Game Edumatika who having the appearance of a whole an interesting and run well. In the material is designed not just as entertainment but also there are learning. Where is the old man has made his son to forget that by learning, because in this game there are also media with at the end of a game there are learning to early childhood. Where is the old man has made his son to forget that by learning, because in this game there are also media with at the end of a game there are learning to early childhood.

Keywords: Game Education, Platformer 2D, Metode Tsukamoto, Linear Congruential Generator (LCG) method.

\section{PENDAHULUAN}

Kemajuan teknologi memang sangat penting untuk kehidupan manusia jaman sekarang. Karena teknologi adalah salah satu penunjang kemajuan manusia. Penggunaan Game Edukasi sebagai alternatif proses pembelajaran tentulah sangat baik karena dinilai baik dan positif, sesuai dengan penelitian yang dilakukan dengan game edukasi ini anak lebih bersemangat dan termotivasi untuk belajar karena anak diajak belajar sambil bermain sehingga tidak menimbulkan rasa bosan pada diri anak. [1]. Dengan adanya aplikasi edukasi tersebut, diharapkan anak - anak usia dini (SD kelas 1) dapat menjadi lebih tertarik untuk belajar sambil bermain. Pada game ini penulis menggunakan Metode Fuzzy Tsukamoto untuk penentuan kondisi perilaku dari Non Player Character(NPC) dimana NPC ini dapat melakukan menyerang dengan cepat, menyerang sedang atau menyerang lambat. Selain menggunakan Metode Fuzzy Tsukamoto pada game ini juga menggunakan Algoritma Linear Congruential Generator (LCG) untuk kemunculan koin di dalam permainan, pada algoritma ini nilai dari koin akan berbeda. Pada game yang akan dibuat nanti yaitu mengenai game perhitungan matematika dasar untuk anak SD kelas 1. Dan akan dilengkapi dengan panduan untuk cara bermain pada game tersebut. Pada game yang akan dibuat dengan menggunakan metode Fuzzy Tsukamoto dan Algoritma Linear Congruential Generator (LCG) ini, diharapkan anak usia dini dapat mengembangkan penerimaan materi, membuat keputusan yang tepat dan bertanggung jawab atas pilihan yang ditentukan sendiri. 
Menurut John von Neumann and Oskar Morgenstern tahun 1944, game adalah "Permainan terdiri atas sekumpulan peraturan yang membangun situasi bersaing dari dua sampai beberapa orang atau kelompok dengan memilih strategi yang dibangun untuk memaksimalkan kemenangan sendiri atau pun untuk meminimalkan kemenangan lawan. Peraturan- peraturan menentukan kemungkinan tindakan untuk setiap pemain, sejumlah keterangan diterima setiap pemain sebagai kemajuan bermain, dan sejumlah kemenangan atau kekalahan dalam berbagai situasi.". Game edukasi adalah game digital yang dirancang untuk pengayaan pendidikan (mendukung pengajaran dan pembelajaran), menggunakan teknologi multimediainteratif.[2]

\section{METODE}

Dalam penelitian ini digunakan metode logika fuzzy tsukamoto dan metode Linear Congruential Generator $(L C G)$. Berikut penjelasan mengenai metode tersebut:

Penerapan logika fuzzy dapat meningkatkan kinerja sistem kendali dengan menekan munculnya fungsifungsi liar pada keluaran yang disebabkan oleh fluktuasi pada variabel masukannya. [3]. Pendekatan logika fuzzy secara garis besar diimplementasikan dalam tiga tahapan sebagai berikut :

1. Tahap pengaburan (fuzzification) yakni pemetaan dari masukan tegas ke himpunan kabur.

2. Tahap inferensi, yakni pembangkitan aturan kabur. Menggunakan fungsi implikasi MIN untuk mendapatkan nilai $\alpha$ - predikat tiap-tiap rule $(\alpha 1, \alpha 2, \alpha 3, \ldots \alpha n)$. Kemudian masing- masing nilai $\alpha$-predikat ini digunakan untuk menghitung keluaran hasil inferensi secara tegas (crips) masingmasing rule $(z 1, z 2, z 3, \ldots z n)$.

3. Tahap penegasan (defuzzification), yakni tranformasi keluaran dari nilai kabur ke nilai tegas. Menggunakan metode rata-rata (average).

$$
\mathrm{Z}^{*}=\sum \frac{\mu(z) z}{\mu(z)}
$$

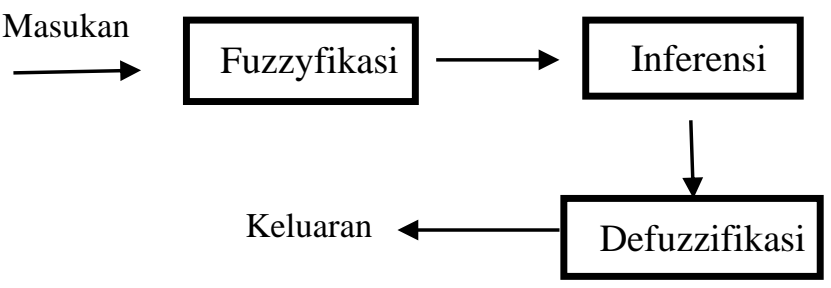

Linear Congruential Generator (LCG) Merupakan salah satu metode pembangkit bilangan acak atau Random Number Generator (RNG) yang merupakan program atau alat untuk menghasilkan urutan angka atau symbol secara tidak teratur. Sistem ini diaplikasikan ke dalam banyak bidang, seperti sampel statistika, simulasi komputer, kriptografi, bahkan untuk desain. Ciri khas dari LCG adalah terjadi perulangan pada periode waktu tertentu atau setelah sekian kali pembangkitan. Penentuan konstanta LCG (a, c dan m) sangat menentukan baik tidaknya bilangan acak yang diperoleh dalam arti memperoleh bilangan acak yang seakan-akan tidak terjadi perulangan (Perbandingan Algoritma Linear Congruential Generators, Blum Blum Shub, dan Mersenne Twister untuk Membangkitkan Bilangan Acak Semu. [4]

Rumus Metode LCG:

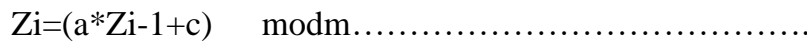

Dimana :

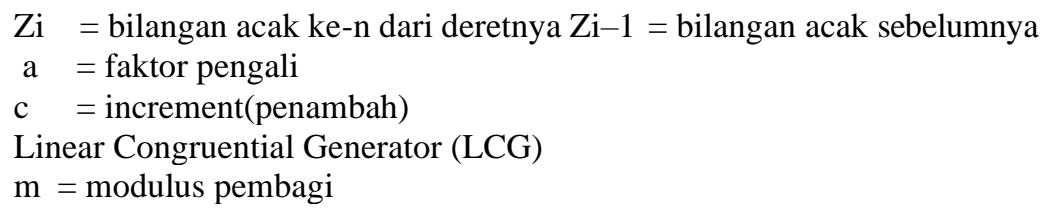

Aplikasi dalam penelitian ini berupa android. Android merupakan OS (Operating System) mobile yang tumbuh ditengah OS lainnya yang berkembang saat ini. OS lainnya seperti Windows Mobile, i-Phone OS, Symbian, dan masih banyak lagi. Akan tetapi, OS yang ada ini berjalan dengan memprioritaskan aplikasi inti yang dibangun sendiri tanpa melihat potensi yang cukup besar dari aplikasi pihak ketiga. Oleh karena itu, 
adanya keterbatasan dari aplikasi pihak ketiga untuk mendapatkan data asli ponsel, berkomunikasi antar proses serta keterbatasan distribusi aplikasi pihak ketiga untuk platform mereka. [5]

\subsection{Metodologi dan Perancangan Sistem}

\subsubsection{Study Literatur}

Studi literature ini sebagai dasar teori yang akan melandasi pengerjaan aplikasi ini dengan mencari literatur - literatur yang berkaitan pada media elektroinik maupun media cetak sebagai bahan untuk pembuatan aplikasi ini.

\subsubsection{Metode PengumpulanData}

Metode pengambilan data yang digunakan dalam penelitian ini adalah pengumpulan data penunjang yang dilakukan dengan pengambilan data- data dari buku mengenai perhitungan Matematika anak SD untuk kelas 1 yang digunakan sebagai landasan teori dalam penelitian ini.

\subsubsection{Metode Perancangan Sistem}

Dalam pengembangan aplikasi game edukasi ini menggunakan metode Mulitimedia Development Life Cyrcle (MDLC). Dimana menggunakan proses metode MDLC terdiri dari beberapa fase yaitu :

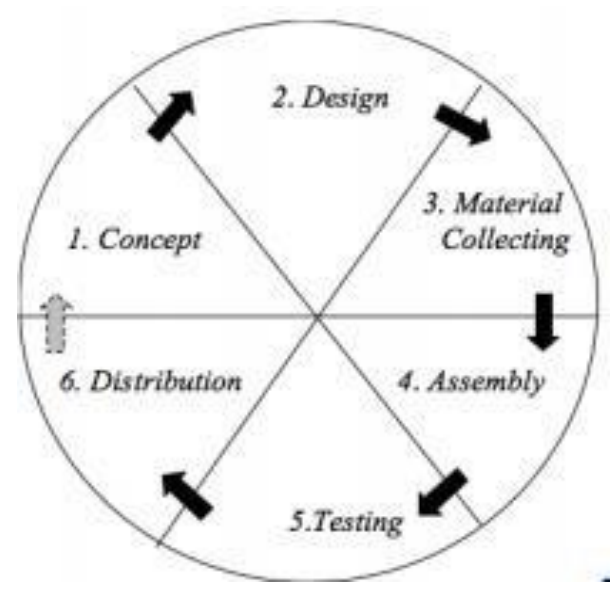

Gambar 1. Model MDLC pada game

\subsection{Perancangan Sistem}

Perancangan sistem merupakan suatu desain sistem sebagai gambaran, perencanaan dan pembuatan sketsa dari sebuah sistem yang akan dibuat. Pada tahap ini menggunakan storyboard untuk menggambarkan deskripsi tiap game, dengan menjelaskan tautan pada game. Storyboard bias dilihat pada Tabel 1. 
Tabel 1. Storyboard Game Study With Doraemon

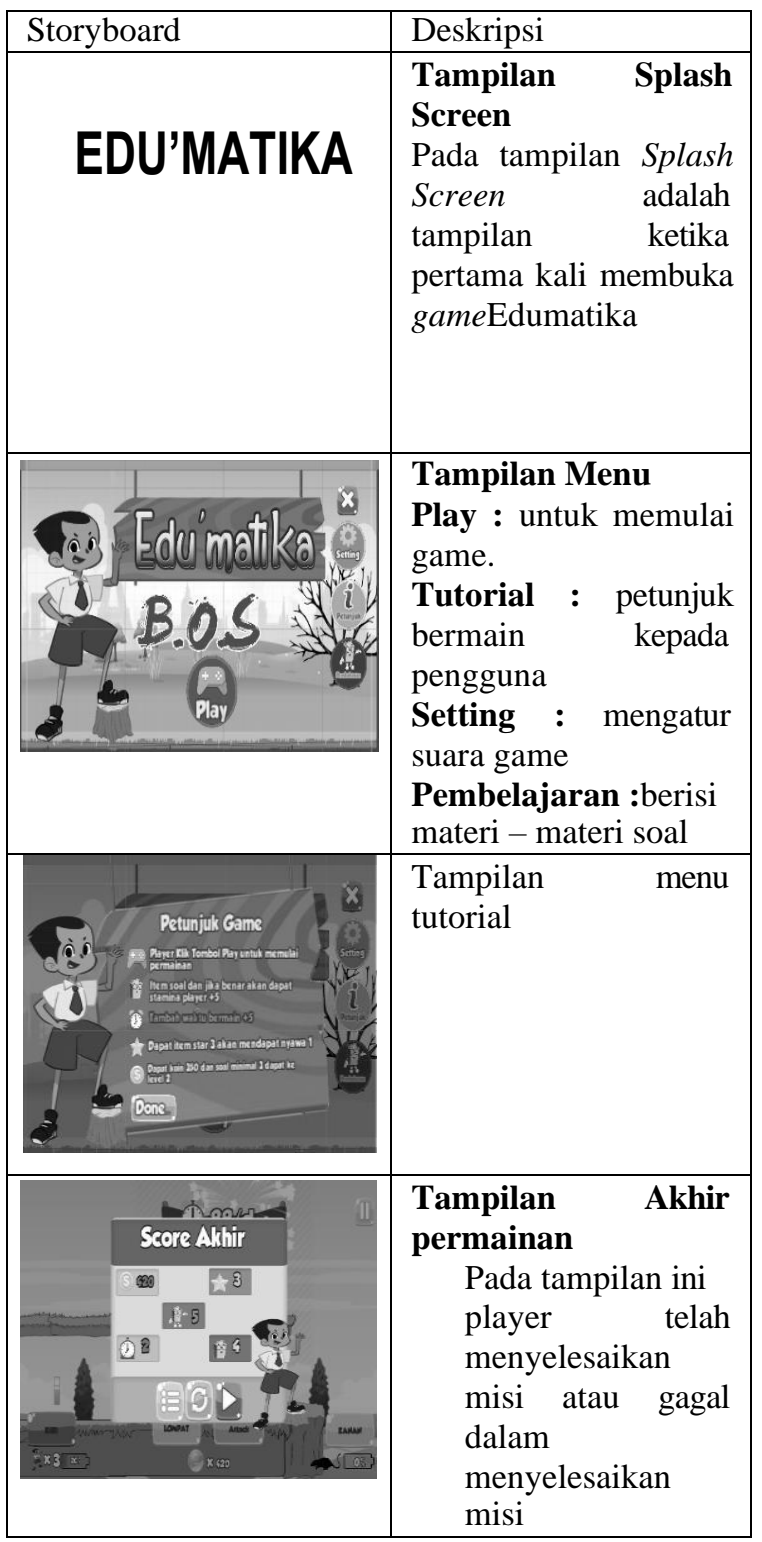

\subsection{Material Collecting}

Pengumpulan bahan adalah tahapan mengumpulkan bahan yang sesuai dengan kebutuhan yang telah direncakan. Bahan yang dibutuhkan meliputi:

Gambar: gambar digunakan dalam pembuatan game, yang dibutuhkan adalah asset button, asset background, asset petunjukgame.

Audio : file audio digunakan sebagai music latar game, suara efek button, suara senjata, suara ambil koin.

Software : kebutuhan perangkat lunak yang digunakan untuk menunjang keperluan pembuatan game seperti game engine Unity, editor gambar CorelDraw X4, dan Photoshop CS3.

\subsection{Testing}

Pengujian (testing) pada game Edumatika dilakukan dengan melakukan pengujian alpha dan betha. Pengujian dilakukan setelah proses pembuatan, pengujian alpha menggunakan metode pengujian BlackBox. Metode ini dilakukan dengan menjalankan aplikasi, kemudian dilihat apakah terjadi kesalahan ketika 60 
menjalankan funsi yang sudah tersedia. Pengujian betha melibatkan pengguna akhir yaitu anak - anak atau masyarakat umum. Pada saat pengujian juga dilakukan penyebaran kuesioner mengenai aplikasi ini, kuesioner yang diberikan berisi pertanyaan yang berhubungan dengan kepuasan dan tercapainya tujuan dari pembuatan game ini.

\section{Pembahasan}

\subsection{Perancangan}

Filtur yang terdapat game Edumatika yaitu player terdapat beberapa menu agar player tidak bingung dalam bermain game seperti тепи petunjuk game sebagai acuan dalam bermain serta menu pembahasan yang berisi materi soal - soal yang akan dikerjakan di dalam game. Dapat dilihat pada gambar 2.

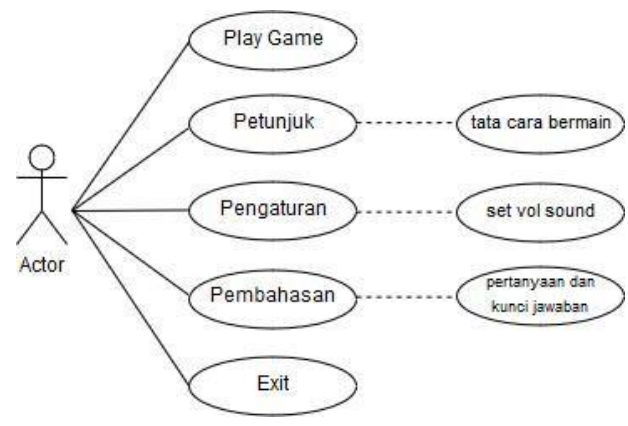

Gambar 2. Usecase game

Gambar 3 merupakan flowchart yang menjelaskan bagaimana game akan berjalan. Player memilih menu start untuk memulai permainan, dimana player akan mengumpulkan koin dan menjawab soal dengan benar agar dapat melanjutkan ke level berikutnya. Jika player tidak dapat menjawab soal dan koin sesuai yang dianjurkan di level pertama maka player tidak dapat melanjutkan ke level berikutnya. Selain mengumpulkan koin dan menjawab soal dengan benar, player dianjurkan untuk mengalahkan NPC yang ada di tiap level.

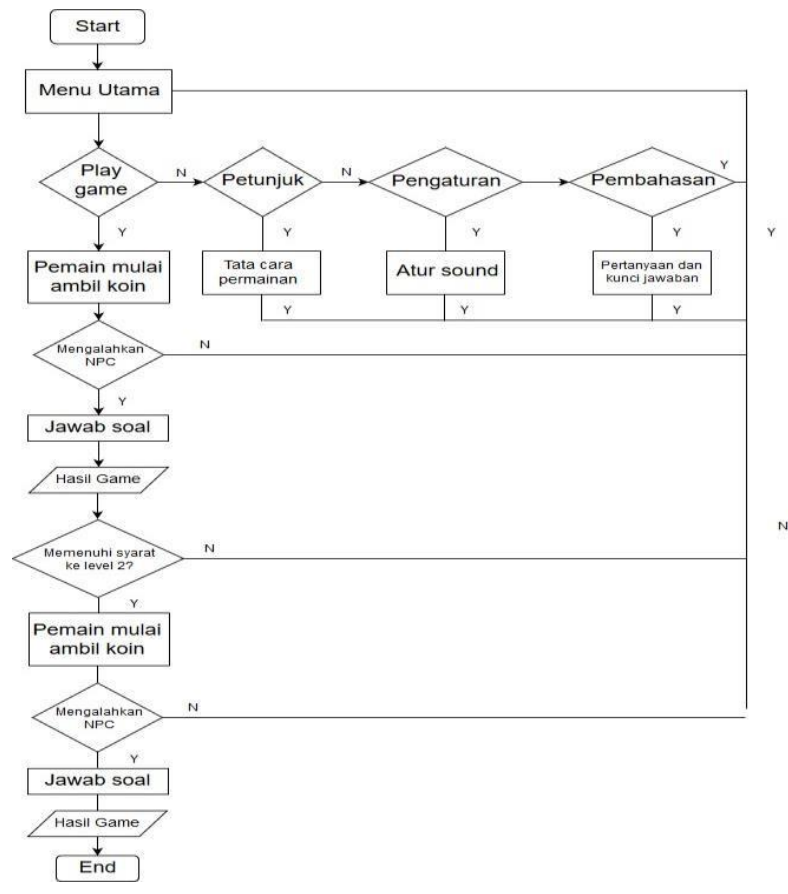

Gambar 3. Flowchart 


\section{Implementasi}

Proses pengimplementasian metode yang akan digunakan pada game "Edumatika" ini yaitu dengan menggunakan range nilai dari beberapa variabel.Variabel jarak, stamina enemy, stamina player dan agresifitas. Gambar 4 sampai 7 merupakan range nilai dari variabel jarak, stamina enemy, stamina player dan agresifitas dengan kategori lambat, cepat dan sedang.

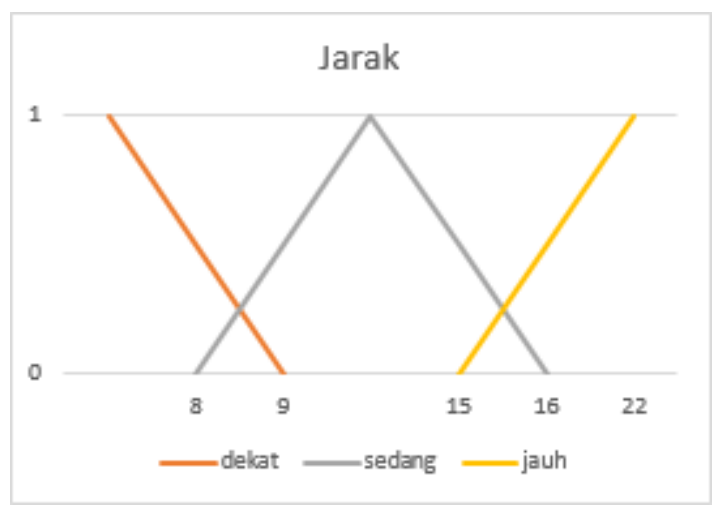

Gambar 4. Variabel Jarak

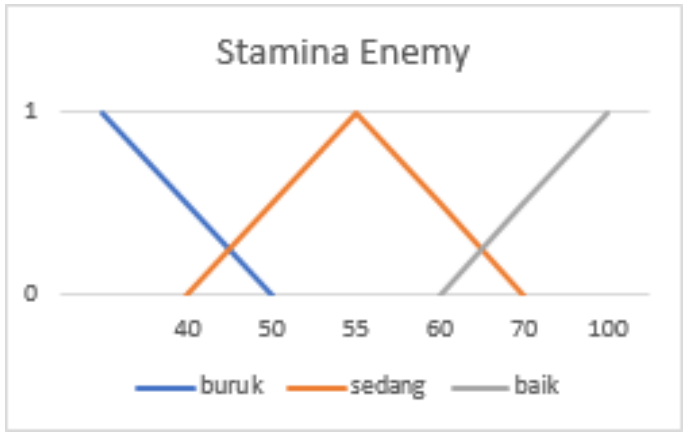

Gambar 5. Variabel Stamina Enemy

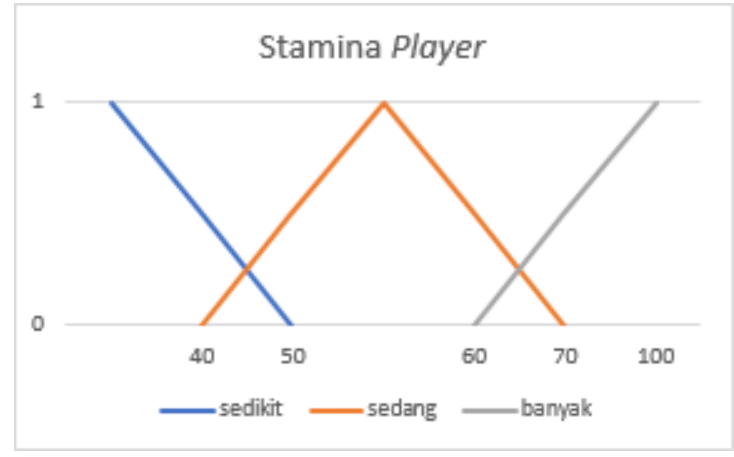

Gambar 6. Variabel Stamina Player 


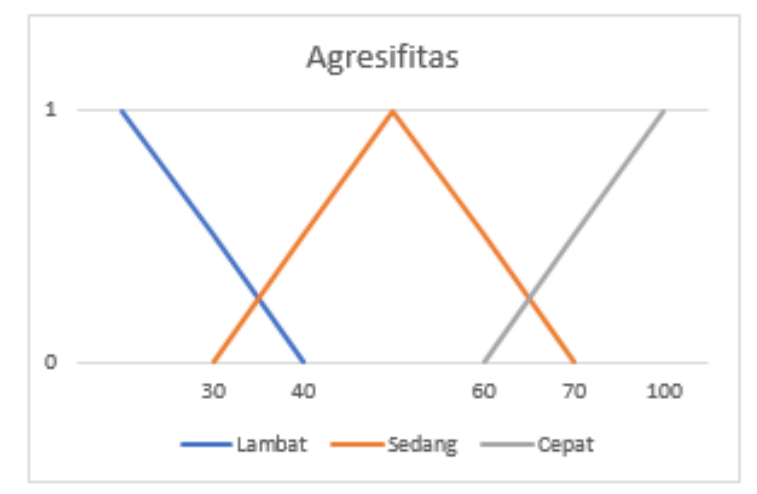

Gambar 7. Variabel Agrefitas

\subsection{Pengujian}

Pengujian terhadap game dengan cara player harus menyelesaikan misi dan mendapatkan item - item yang ditentukan setiap level permainan. Hasil pengujian tersebut dapat dilihat pada tabel 2.

Tabel 2. Pengujian gameplay

\begin{tabular}{|c|l|l|l|}
\hline \multicolumn{1}{|c|}{$\begin{array}{c}\text { Kelas } \\
\text { Uji }\end{array}$} & $\begin{array}{l}\text { Skenario } \\
\text { Uji }\end{array}$ & $\begin{array}{l}\text { Hasilyang } \\
\text { diharapkan }\end{array}$ & Hasil Uji \\
\hline Poin & $\begin{array}{l}\text { Player } \\
\text { mengambil } \\
\text { item dan } \\
\text { mengalahka } \\
\text { n musuh }\end{array}$ & $\begin{array}{l}\text { Poin } \\
\text { mengalami } \\
\text { penambahan }\end{array}$ & Berhasil \\
\hline Waktu & $\begin{array}{l}\text { Waktu } \\
\text { permainan }\end{array}$ & $\begin{array}{l}\text { Waktu } \\
\text { berjalan } \\
\text { mundur }\end{array}$ & Berhasil \\
\hline Stamina & $\begin{array}{l}\text { Player } \\
\text { mengambil } \\
\text { item berupa } \\
\text { koin emas, } \\
\text { buku, jam } \\
\text { weker dan } \\
\text { star }\end{array}$ & $\begin{array}{l}\text { Score } \\
\text { mengalami } \\
\text { penambahan }\end{array}$ & Berhasil \\
Player & $\begin{array}{l}\text { Player } \\
\text { mengambil } \\
\text { stamina } \\
\text { power } \\
\text { berupa buku } \\
\text { untuk } \\
\text { menambah } \\
\text { stamina, }\end{array}$ & $\begin{array}{l}\text { Stamina } \\
\text { Player } \\
\text { mengalami } \\
\text { perubahan }\end{array}$ & Berhasil \\
\hline $\begin{array}{l}\text { player } \\
\text { terkena } \\
\text { jebakan, } \\
\text { jatuh, } \\
\text { dan } \\
\text { ditembak } \\
\text { enemy } \\
\text { dapat } \\
\text { mengurangi } \\
\text { stamina }\end{array}$ & & \\
\hline
\end{tabular}




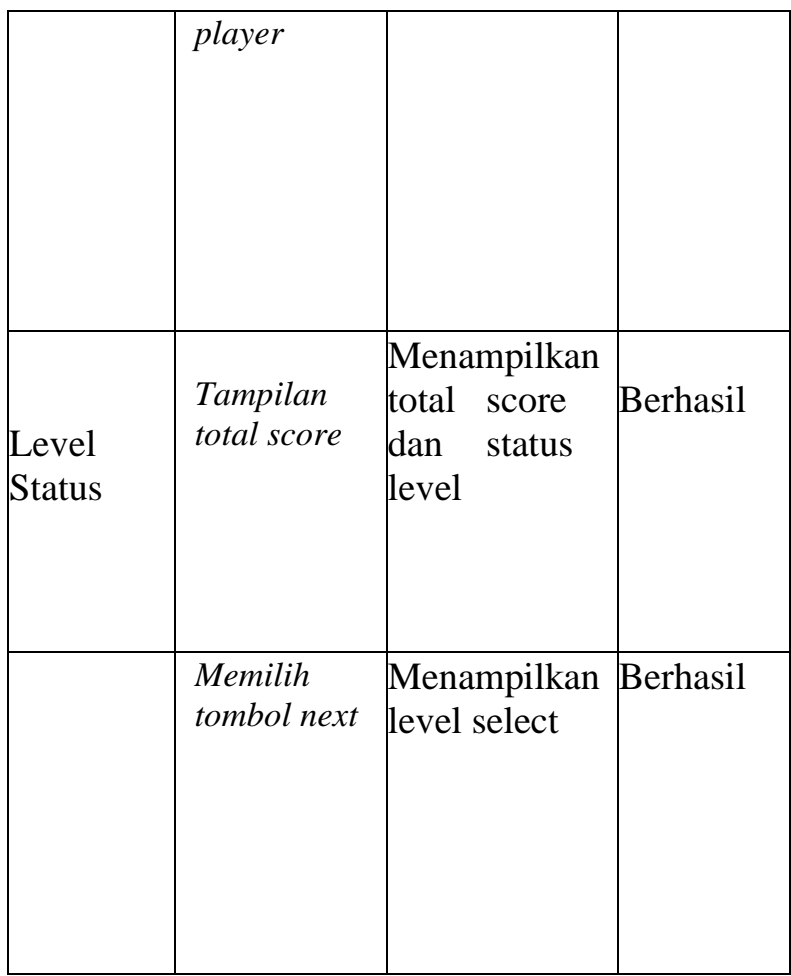

Pengujian kelayakan game dapat dinilai dengan menggunakan kuesioner atau angket terhadap calon responden atau calon pengguna aplikasi.Kuesioner tersebut diberikan kepada 10 anak yang berusian $10-12$ tahun dengan dibuat skala jawaban 1 sampai 3. Daftar pertanyaan kuesioner dapat dilihat pada tabel 3.

Tabel 3. Daftar Pertanyaan Pada Kuesioner

\begin{tabular}{|c|c|c|c|c|}
\hline \multirow[t]{2}{*}{ No. } & \multirow[t]{2}{*}{ Pertanyaan } & \multicolumn{3}{|c|}{$\begin{array}{c}\text { Skala } \\
\text { Jawaban }\end{array}$} \\
\hline & & 1 & 2 & 3 \\
\hline 1. & $\begin{array}{lrr}\text { Apakah } & \text { Tampilan } & \text { game } \\
\text { "Edumatika" } & \text { secara } & \text { umum } \\
\text { menarik? } & & \end{array}$ & & & \\
\hline 2. & $\begin{array}{l}\text { Apakah tingkat kesulitan } \\
\text { permainan dalam game } \\
\text { "Edumatika" sudah sesuai dengan } \\
\text { tingkat level? }\end{array}$ & & & \\
\hline 3. & $\begin{array}{l}\text { Apakah game "Edumatika" } \\
\text { menarik untuk dimainkan? }\end{array}$ & & & \\
\hline 4. & $\begin{array}{l}\text { Apakah game "Edumatika" sulit } \\
\text { dimainkan? }\end{array}$ & & & \\
\hline 5. & $\begin{array}{l}\text { Apakah karakter dalam game } \\
\text { "Edumatika" menarik? }\end{array}$ & & & \\
\hline
\end{tabular}




\begin{tabular}{|l|l|l|l|l|}
\hline 6. & $\begin{array}{l}\text { Apakah gambar pada game } \\
\text { "Edumatika" menarik dan terlihat } \\
\text { jelas? }\end{array}$ & & & \\
\hline 7. & $\begin{array}{l}\text { Apakah tombol arah padadalam } \\
\text { game "Edumatika" mudah }\end{array}$ & & & \\
\hline & digunakan? & & & \\
\hline 8. & $\begin{array}{l}\text { Apakah suara dalam game } \\
\text { "Edumatika" sudah sesuai? }\end{array}$ & & & \\
\hline
\end{tabular}

$$
\begin{array}{cll}
\text { Keterangan } & : \\
3 & =\text { Sangat Setuju } \\
2 & =\text { Cukup } \\
1 & =\text { Kurang Setuju }
\end{array}
$$

\subsection{Pembahasan}

Hasil dari kuisioner yang sudah diisi, kemudian nilai dari setiap pertanyaan diperoleh tabel 4 seperti berikut ini :

Tabel 4. Hasil Kuisioner

\begin{tabular}{|c|l|c|c|c|c|c|c|c|c|c|c|}
\hline \multirow{2}{*}{ No } & \multirow{2}{*}{ Nama } & \multirow{2}{*}{ Umur } & \multirow{2}{*}{ JK } & \multicolumn{7}{|c|}{ Pertanyaan } \\
\cline { 5 - 11 } 1 & Sasa & 7 & P & 2 & 2 & 2 & 2 & 1 & 2 & 2 & 1 \\
\hline 2 & Dita & 6 & L & 2 & 2 & 1 & 2 & 2 & 1 & 1 & 2 \\
\hline 3 & Tegar & 6 & L & 2 & 1 & 2 & 1 & 2 & 2 & 2 & 1 \\
\hline 4 & Jovan & 6 & L & 2 & 2 & 2 & 3 & 2 & 2 & 1 & 1 \\
\hline 5 & Yogis & 9 & L & 2 & 1 & 2 & 2 & 2 & 2 & 1 & 1 \\
\hline 6 & Ridhoi & 7 & L & 2 & 1 & 2 & 2 & 2 & 2 & 1 & 1 \\
\hline 7 & Renbi & 8 & L & 2 & 2 & 2 & 2 & 2 & 2 & 1 & 1 \\
\hline 8 & Abi & 7 & L & 2 & 2 & 2 & 1 & 2 & 2 & 2 & 1 \\
\hline 9 & Rifki & 6 & L & 1 & 2 & 1 & 2 & 2 & 2 & 1 & 1 \\
\hline 10 & Wawa & 6 & P & 2 & 1 & 2 & 2 & 2 & 2 & 1 & 2 \\
\hline
\end{tabular}

Berdasarkan hasil kuesioner pada table diatas, dicari prosentase masing-masing jawaban dengan menggunakan rumus :

$$
\mathrm{H}=\mathrm{J} / \mathrm{U} * 100 \%
$$


Keterangan:

$\mathrm{H}=$ Hasil perhitungan

$\mathrm{J}=$ Banyaknya jawaban (skala jawaban) oleh Responden

$\mathrm{U}=$ Jumlah User

Untuk proses prosentasi dari setiap pertanyaan pada kuisioner yang telah dilakukan oleh10 user berikut ini prosentase dari pertanyaan kuisioner.

a. Pertanyaan pertama, Apakah TampilanGame Edumatika menarik?

Tabel 5. Hasil Pertanyaan Pertama

\begin{tabular}{|l|c|c|c|}
\hline $\begin{array}{l}\text { Skala } \\
\text { Jawaban }\end{array}$ & 1 & 2 & 3 \\
\hline Responden & 1 & 9 & 0 \\
\hline Hasil & $10 \%$ & $90 \%$ & $0 \%$ \\
\hline
\end{tabular}

Berdasarkan dari hasil tabel 5, bahwa dari 10 responden sebanyak 1 responden menjawab dengan tidak setuju dengan prosentase $10 \%$ dan 9 responden menjawab setuju dengan prosentase $90 \%$. Dengan hasil tersebut dapat disimpulkan bahwa tampilan Game Edumatika disenangi oleh pengguna.

b. Pertanyaan kedua, Apakah tingkat kesulitan permainan dalam Game Edumatika sudah sesuai dengan tingkatlevel?

Tabel 6. Hasil Pertanyaan Kedua

\begin{tabular}{|c|c|c|c|}
\hline Skala Jawaban & 1 & 2 & 3 \\
\hline Responden & 4 & 6 & 0 \\
\hline Hasil & $40 \%$ & $60 \%$ & $0 \%$ \\
\hline
\end{tabular}

Berdasarkan tabel 6, menunjukkan hasil bahwa sebanyak 4 responden menjawab tidak setuju dengan prosentase $40 \%, 6$ responden menjawab setuju dengan prosentase $60 \%$. Dengan hasil tersebut dapat disimpulkan bahwa tingkat kesulitan dalam bermain game Edumatika sudah sesuai dengan tingkat level.

c. Pertanyaan ketiga, Apakah game Edumatika menarik untukdimainkan?

Tabel 7. Hasil Pertanyaan Ketiga

\begin{tabular}{|c|c|c|c|}
\hline Skala Jawaban & 1 & 2 & 3 \\
\hline Responden & 2 & 8 & 0 \\
\hline Hasil & $2 \%$ & $80 \%$ & $0 \%$ \\
\hline
\end{tabular}

Berdasarkan tabel 7, menunjukkan hasil bahwa sebanyak 4 responden menjawab tidak setuju dengan prosentase $20 \%$ dan 8 responden menjawab setuju dengan prosentase $80 \%$. Dengan hasil tersebut dapat disimpulkan bahwa Game Edumatika menarik untuk dimainkan.

d. Pertanyaan keempat, Apakah Game Edumatika sulitdimainkan? 
Tabel 8. Hasil Pertanyaan Ketiga

\begin{tabular}{|c|c|c|c|}
\hline Skala Jawaban & 1 & 2 & 3 \\
\hline Responden & 2 & 7 & 1 \\
\hline Hasil & $20 \%$ & $70 \%$ & $10 \%$ \\
\hline
\end{tabular}

Berdasarkan tabel 8, menunjukkan hasil bahwa sebanyak 7 responden menjawab tidak setuju dengan prosentase 20\%, 7 responden menjawab setuju dengan prosentase $70 \%$, dan 1 responden menjawab sangat setuju dengan prosentase $10 \%$. Dengan hasil tersebut dapat disimpulkan bahwa game Edumatika mudah digunakan.

e. Pertanyaan kelima, Apakah karakterdalam Game Edumatika menarik?

Tabel 9. Hasil Pertanyaan Kelima

\begin{tabular}{|c|c|c|c|}
\hline Skala Jawaban & 1 & 2 & 3 \\
\hline Responden & 1 & 9 & 0 \\
\hline Hasil & $10 \%$ & $90 \%$ & $0 \%$ \\
\hline
\end{tabular}

Berdasarkan tabel 9, menunjukkan hasil bahwa sebanyak 9 menjawab tidak setuju dengan prosentase 10\%, 9 responden menjawab setuju dengan prosentase $90 \%$. Dengan hasil tersebut dapat disimpulkan bahwa game Edumatika sudah sesuai dengan karakter yang dibuat.

f. Pertanyaan keenam, Apakah tampilan soal padaGame Edumatika terlihat jelas?

Tabel 10. Hasil Pertanyaan Keenam

\begin{tabular}{|c|c|c|c|}
\hline Skala Jawaban & 1 & 2 & 3 \\
\hline Responden & 1 & 9 & 0 \\
\hline Hasil & $1 \%$ & $90 \%$ & $0 \%$ \\
\hline
\end{tabular}

Berdasarkan tabel 10 dapat dilihat bahwa dari 1 responden menjawab tidak setuju dengan prosentase $10 \%$ dan 9 responden menjawab setuju dengan prosentase $90 \%$. Dengan hasil tersebut dapat disimpulkan bahwa tampilan soal pada game "Edumatika" sudah terlihat jelas

g. Pertanyaan ketujuh, Apakah tombol arah dalamGame Edumatika mudah digunakan?

Tabel 11. Hasil Pertanyaan Ketujuh

\begin{tabular}{|c|c|c|c|}
\hline Skala Jawaban & 1 & 2 & 3 \\
\hline Responden & 7 & 3 & 0 \\
\hline Hasil & $70 \%$ & $30 \%$ & $0 \%$ \\
\hline
\end{tabular}

Berdasarkan tabel 11 dapat dilihat bahwa dari 7 responden menjawab tidak setuju dengan prosentase $70 \%$ dan 3 responden menjawab setuju dengan prosentase 30\%. Dengan hasil tersebut dapat disimpulkan bahwa tampilan soal pada game "Edumatika" mudah digunakan.

h. Pertanyaan kedelapan, Apakah suara dalam Game Edumatika sudah sesuai dan terdengar jelas?

Tabel 12. Hasil Pertanyaan Kedelapan

\begin{tabular}{|c|c|c|c|}
\hline Skala Jawaban & 1 & 2 & 3 \\
\hline Responden & 8 & 2 & 0 \\
\hline Hasil & $80 \%$ & $20 \%$ & $0 \%$ \\
\hline
\end{tabular}

Berdasarkan tabel 11, dapat dilihat bahwa dari 8 responden menjawab tidak setuju dengan prosentase $80 \%$ dan 2 responden menjawab setuju dengan prosentase $20 \%$. Dengan hasil tersebut dapat disimpulkan bahwa suaradalam gameedumatika terdengar jelas. 


\section{Kesimpulan dan Saran}

5.1 Kesimpulan

Berdasarkan penelitian yang dilakukan pada aplikasi game Edumatika menggunakan metode Fuzzy Tsukamoto dan metode Algoritmat Linear Congruential Generator (LCG) dapat disimpulkan :

i. $\quad$ Aplikasi ini telah berhasil menerapkan metode Fuzzy Tsukamoto dan metode Algoritma Linear Congruential Generator untuk gameEdumatika.

ii. Dapat membuat anak usia dini dan pengguna belajar dan bermain secara bersamaan.

\subsection{Saran}

iii. Dapat membuat aplikasi sebagai sarana pembelajaran untuk anak SD kelas1

Berdasarkan penelitian ini ada beberapa saran untuk game ini yaitu sebagai berikut :Kurang adanya cerita latar belakang yang mendasari dari alur permainan ini. Diharapkan untuk kedepannya dapat penambahan latar belakang mengenai materi yang disampaikan.

\section{DAFTAR RUJUKAN}

Dahlan Abdullah (2015). Aplikasi Kuis Pengetahuan Umum Berbasis Web Menggunakan Metode Linear Congruential Generators. Aceh : UNIVERSITAS MALIKUSSALEH REULEUT

Dwi Sri. (2015). Pengembangan Game Puzzel sebagai media pembelajaran huruf Jepang Hiragana dan Katakana menggunakan Metode Fisher-Yates Shuffle dan Metode Fuzzy Tsukamoto berbasis Android. Malang : Politeknik NegeriMalang.

Marzuki, F. C. (-). GAME BERBASIS ADVENTURE SEBAGAI PENDUKUNG PEMBELAJARANPENGENALAN KATA BAHASA INGGRIS UNTUK ANAK USIA DINI . Jurnal Sistem Informasi dan Telematika , -(2087-2062 ), 2-4

Haditama Imam, dkk (2016). Implementasi Algoritma Fisher - Yates dan Fuzzy Tsukamoto dalam Game Kuis Tebak Nada Sunda Berbasis Android. Bandung : Universitas Islam Negeri Sunan Gunung Djati Bandung.

Andang Ismail. (2009). Education Games Pilar Media.Yogyakarta.

Kurniawan Teguh Martono (2015,Vol 5,1). Pengembangan Game Dengan Menggunakan Game Engine Game Maker. Semarang : Universitas Diponegoro Semarang.

Rika Nomilasari. (2016) Rancang Bangun game Smart Chicken Menggunakan Metode Fuzzy Tsukamoto. Malang : Politeknik NegeriMalang.

Rizkyna Cahyaningrum. (2016). Implementasi Metode Fisher-Yates Shufle dan Fuzzy Tsukamoto pada game 2D Gopoh Berbasis Android. Malang : Politeknik Negeri Malang.

Roby Gunawan Baskoro, Awang Harsa Kridalaksana, Helisa Rahmania Hatta. (2016). Membangun Game Simulasi Best Driver dengan menggunakan Metode Fuzzy Tsukamoto berbasis Multiplatform. Kalimantan Timur.

Nonok Eko Wahyu Riswono. (2016). 3D Adventure Game Untuk Belajar Al-Qur'an Dengan Menggunakan Metode Fuzzy Tsukamoto. Malang : Universitas Islam Negeri Maulana Malik Ibrahim Malang 